\title{
Article \\ Isolation, identification and antibiogram profiles of enterovirulent Escherichia coli from diarrhoeic goat in some selected areas of Rangpur district of Bangladesh
}

\author{
Md. Rashed Kamal, Md. Fakhruzzaman, Mir Rowshan Akter and Md. Atiqul Haque* \\ Department of Microbiology, Hajee Mohammad Danesh Science and Technology University, Dinajpur-5200, \\ Bangladesh \\ *Corresponding author: Dr. Md. Atiqul Haque, Assistant Professor, Department of Microbiology, Faculty of \\ Veterinary and Animal Science, Hajee Mohammad Danesh Science and Tecnology University, Dinajpur-5200, \\ Bangladesh. Phone: +8801717210631; E-mail: atique@ hstu.ac.bd
}

Received: 26 February 2018/Accepted: 19 March 2018/ Published: 29 March 2018

\begin{abstract}
Enterovirulent Escherichia coli remain as an important etiological agent of goat diarrhoea in Bangladesh. The present study was designed with a view to isolate and identifies $E$. coli from field cases. For this purpose, a total of 135 faecal samples (85 from diarrhoeic and 50 from apparently healthy goat) were collected during the period from January 2012 to July 2012 from different areas in Rangpur District. It was found that the prevalence of $E$. coli was higher (18.82 \%) in diarrhoeic goats while it was lower (14.00\%) in non diarrhoeic goats. Age wise distribution of $E$. coli isolates were $26.42 \%$ in day old to 1 year, $10.53 \%$ in $1-2$ years and $11.36 \%$ in above 2 years age of goat respectively. All the isolates of $E$. coli revealed greenish black colony with metallic sheen in Eosine methylene blue agar, bright pink color smooth transparent colony in MacConkey agar and slight pinkish smooth colony in Salmonella-Shigella agar. Gram stain and hanging drop techniques were performed with the cultured bacteria. Biochemical properties of the isolates were studied, and antibiotic sensitivity test was done by agar disk diffusion method. In Gram stain, the organisms revealed Gram negative, small rod shaped, occurs singly or paired. Biochemically, all of the isolates showed fermentation of dextrose, sucrose and maltose with the production of acid and gas, negative result to Voges-Proskauer test, positive result to Methylred test and differential result to Indol test. All the isolates of E. coli were highly sensitive to ciprofloxacin and gentamicin while moderately sensitive to colistin, livofloxacin and azithromycin and less sensitive to ceftraexon and tetracyclin and resistant to amoxycillin, ampicillin, erythromycin, and neomycin. Therefore, ciprofloxacin and gentamicin may be the antibiotics of first choice, and colistin, livofloxacin and azithromycin may be the second choice among the test antibiotics for the treatment of illness caused by these bacteria.
\end{abstract}

Keywords: Escherichia coli; diarrhoea; goat; antibiogram

\section{Introduction}

The major community health hazards both for men and animals in most countries of the world are diarrhoeal disease. It is resulted from the enteritis, which is the inflammation of the intestinal mucosa, characterized by abdominal pain, loose faeces, increase in faeces volume, faeces frequency, nausea or faeces fluidity that contain 70-95\% water (dehydration). Several liter of fluid may be lost per day in severe cases of diarrhoea. The chronic form of diarrhoea may last for days or weeks and may culminate in death (Radostits et al., 1995). Diarrhoea of caprine occurs worldwide in goats of any age. Goat diarrhoea is responsible for poor growth in kids and a momentous loss of production both through morbidity and mortality. Some enteropathogens like bacteria, viruses, protozoa and helminths have been recognized to be associated with diarrhoea (Radostits et al., 1995). Escherichia coli (E. coli) is one of them. 
E. coli a member of family Enterobacteriaceae is a short rod shaped, Gram negative, non-spore forming and usually peritrichous and fimbriate bacillus. A capsule or microcapsule is often present and a few strains produce profuse polysaccharide slime. E. coli was first isolated by Theobald Escherich in 1885 from faeces of infants. It serves as a major facultative anaerobe throughout its life as a harmless saprophyte but Larulle (1889) was the first to suggest the possible role of E. coli as a pathogenic organism. E. coli has been shown to be a normal inhabitant of the gastrointestinal tract of animal and man (Smith, 1965). The organism typically colonizes the infant gastrointestinal tract within hours of life and thereafter, both $E$. coli and the host derive mutual benefit (Drasar and Hill, 1974). In the debilitated or immunosupressed host or when gastrointestinal barriers are violated even normal non pathogenic strains of $E$. coli can cause infection. Enterovirulent or pathogenic E. coli is one of the most important groups of bacteria causing diarrhoea and extra intestinal infections in humans and animals (Levine, 1987). Escherichia coli is considered as the normal bowel flora of different species of mammals and birds but some strains of $E$. coli possess pathogenic character due to the acquisition of virulent factors. Microbial characteristics associated with virulent E. coli include production of enterotoxin, verotoxin, colicins and siderophores, type-1 pili and motility, resistance to the lytic action of the host complement and antibiotics (Dho and Lafont, 1984; Chulasiri and Suthienkul, 1989).

The enteric E. coli are divided into six groups on the basis of their virulence properties such as enterotoxigenic (ETEC, causative agent of diarrhoea in humans, pigs, sheeps, goats, cattle, dogs and horses), enteropathogenic (EPEC, causative agent of diarrhoea in humans, rabbits, dogs, cats and horses), enteroinvasive (EIEC, found only in humans), verotoxigenic (VTEC, found in pigs, cattle, dogs and cats), enterohaemorrhagic (EHEC, found in human, cattle, and goats) and enteroaggregative E. coli (EAggEC, found only in human). E. coli is a major pathogen of commercial poultry causing colibacillosis with manifestations such as airsacculitis, pericarditis, septicaemia, and death of the birds (about 28\% deaths in Sonali birds) (Biswas et al., 2006). Enterotoxigenic E. coli (ETEC) is a major pathogen of animals, being responsible for diarrhoea in calves, lambs and goat kids resulting significant financial losses. Debnath et al. (1990) claimed 28\% of the total death in calves occurred in first month of life and $50 \%$ of death during first week due to E. coli infection. It also causes on-farm contamination of different animal species (Fairbrother and Nadeau, 2006). ETEC is the most common cause of food and water-borne human diarrhoea worldwide. In developing countries, the incidence of enteric diseases due to ETEC is estimated about 650 million cases per year, resulting in 800,000 deaths, primarily in children of below five years old (Turner et al., 2006). So E. coli is an important zoonotic pathogen.

Goat rearing has become seriously impaired due to high mortality with diarrhoea like symptoms. The marginal and land-less farmers most easily live on rearing of goats in Bangladesh. So, goat is called the poor man's cow that is the second important livestock in Bangladesh which plays an important role in the rural economy and we can earn substantial amount of foreign currency by exporting skin and other by-products. Goats are very susceptible to E. coli infection. Two age groups appear to be susceptible, goats of 1-3 days of age and goats of 4-8 weeks old. Symptoms include diarrhoea, a rise in temperature, weakness and lack of appetite. This is soon followed by coma and death within a few hours. In older animals there is a tendency or infection to localize itself in the joints of survivors. Lesions include enlarged, haemorrhagic spleens, and the accumulation of synovial fluid and sometimes pus in affected joints (Blood et al., 1968). The E. coli infection is a disease of economic importance. The mortality rate due to E. coli infection in young age goat is higher of then older (Radostits et al., 1995). Due to E. coli infection in goat meat production is declined considerably. As a result the farmers who are economically dependent on goat rearing become looser.

Cultural characterization of $E$. coli by using different media and biochemical characterization by observing variable reaction to different sugars and chemicals are the basic rules for their identification. Zinnah, 2007 conducted an experiment on E. coli isolated from human, cattle, sheep, goat, chickens, duck, pigeon, drain sewages and soil. Antibiotics are widely used in case of diseased animal in the treatment of goat diarrhoea. In the context of Bangladesh, for many years antibiotic is randomly used for the treatment purpose. Knowledge of local antimicrobial therapy pattern is important in selecting the appropriate therapy. For the prevention and control of any microbial disease, prior isolation, identification and characterization of that particular etiological agent in a country is a precondition. The current study was undertaken to isolate and identify $E$. coli from the field cases and also to identify and selection of specific drugs to treat goat diarrhoea.

\section{Materials and Methods}

\subsection{Sample collection}

A total of 135 faecal samples were collected from different Veterinary hospitals in Rangpur District as shown in Table 1. Faeces were collected directly from rectum of goats with a history of suffering from diarrhoea and also apparently healthy one. About 05-10 grams of faeces were collected from each animal by using clean plastic 
gloves and kept in a sterilized screw caped vial. All the samples were collected aseptically from the rectum by using finger or directly from fallen faeces. The samples were carried to the Bacteriology Laboratory of the Department of Microbiology, Hajee Mohammad Danesh Science and Technology University (HSTU), Dinajpur, Bangladesh in an ice box contained ice and processed for the isolation and characterization of bacteria subsequently. And the remaining samples were stored at $4^{\circ} \mathrm{C}$ for further use.

\subsection{Laboratory preparation}

All items of glass wares including test tubes, pipettes, cylinder, flasks, conical flasks, glass plate, slides, vials soaked in a household dishwashing detergent solution ('Trix' Recket and Colman Bangladesh Ltd.) for overnight, contaminated glassware were disinfected in $2 \%$ sodium hypochloride solution prior to cleaning. The glassware were then cleaned by brushing, washed thoroughly and finally sterilized either by dry heat at $160^{\circ} \mathrm{C}$ for 2 hours or by autoclaving for 15 minutes at $121^{\circ} \mathrm{C}$ under $15 \mathrm{lbs}$ pressure per square inch. Autoclaved items were dried in a hot air oven over at $50^{\circ} \mathrm{C}$. Disposable plastic were (micropipette tips) was sterilized by autoclaving. All the glassware was kept in oven at $50^{\circ} \mathrm{C}$ for future use.

\subsection{Bacteriological examination of feacal sample}

$1 \%$ Sterile peptone water was added to all feacal samples and mixed to give a semi-solid consistency and bacterial culture was done for individual pathogens as described by Merchant and Packer (1976), OIE (2000) and Carter (1991). The samples were first cultured into the nonselective enriched media such as nutrient broth (NB) and nutrient agar (NA) media and incubated at $37^{\circ} \mathrm{C}$ for 24 to $48 \mathrm{hrs}$ for the growth of bacteria. Then the samples were subcultured into the different selective media and incubated at $37^{\circ} \mathrm{C}$ for 24 to 48 hrs for identification of bacteria by their morphological characteristics including size, shape, surface texture, edge, elevation, color, opacity etc. were studied as described by Merchant and Packer (1976). The media used were MacConkey (MC) agar, Eosin Methylene Blue (EMB) agar, Salmonella-Shigella (SS) agar, Mueller Hinton (MH) agar, Triple sugar iron (TSI) agar, Basic sugar media (dextrose, lactose, mannitol and maltose), Motility Indole Urease (MIU) agar base media, Methyle Red-Voges Proskauer medium base. Several biochemical tests such as Indole test, MIU test, Methyl red (MR) test, Voges-Proskauer (VP) test, Triple Sugar Iron test and Carbohydrate fermentation test were performed according to Holt et al. (1994) to identify the biochemical characteristics of the bacterial isolates.

\subsubsection{Bacterial motility test}

The motility test was performed to differentiate motile bacteria from the non-motile one. Before performing the test, a pure culture of the organism was allowed to grow in Nutrient broth. One drop of cultured broth was placed on the coverslip and was placed invertedly over the concave depression of the hanging drop slide to make hanging drop preparation. Vaseline was used around the concave depression of the hanging drop slide for better attachment of the coverslip to prevent air current and evaporation of the fluid. The hanging drop slide was then examined carefully under 100 power objective of a compound microscope using immersion oil. Movement of organism under microscope was observed due to presence of flagella/fimbri (Cowan, 1985).

\subsubsection{Determination of morphology of bacteria by Gram's staining method}

The Gram's staining method was performed as described by Merchant and Packer (1976). Briefly, a small colony was picked up with a bacteriological loop, smeared on a glass slide and fixed by gentle heating. Crystal violet solution was then applied on the smear to stain for two minutes and then washed with running water. Gram's iodine was added to act as mordent for one minutes and then again washed with running water. Acetone alcohol was then added, which act as a decolorizer. After 10 second washing with water and safranine was added as counter stain and allowed to stain for 1 to 2 minutes. Then the slide was washed with water, blotted and dried in air and then examined under microscope with $100 \times$ objectives.

\subsection{Antimicrobial susceptibility test}

The antimicrobial susceptibility test for E. coli was performed on freshly prepared Mueller Hinton agar (HiMedia, India) by disc diffusion method, as described by Khan et al. (2005). Ten different antibacterial disc (CARTIDGE DISC), manufactured by MAST DIAGNOSTICS, Merseyside, UK were selected, vizAmoxicillin $(25 \mu \mathrm{g} / \mathrm{disc})$, Ampicillin $(10 \mu \mathrm{g} / \mathrm{disc})$, Levofloxacine $(5 \mu \mathrm{g} / \mathrm{disc})$, Ciprofloxacin $(5 \mu \mathrm{g} / \mathrm{disc})$, Ceftraexon (30 $\mu \mathrm{g} / \mathrm{disc})$, Cloxacillin $(5 \mu \mathrm{g} / \mathrm{disc})$, Gentamicin $(10 \mu \mathrm{g} / \mathrm{disc})$, Tetracycline $(30 \mu \mathrm{g} / \mathrm{disc})$, Neomycin (30 $\mu \mathrm{g} / \mathrm{disc})$, Colistin sulphate $(25 \mu \mathrm{g} / \mathrm{disc})$, Azithromycin $(15 \mu \mathrm{g} / \mathrm{disc})$ and Erythromycin $(15 \mu \mathrm{g} / \mathrm{disc})$. The 
isolated bacteria were analyzed for antimicrobial susceptibility test were expressed as either resistant or sensitive, as per the guidelines of Clinical and Laboratory Standard Institute (CLSI, 2012).

\section{Results and Discussion}

Among bacterial pathogens worldwide, enterovirulent Escherichia coli ranks among the most common causative agents of bacterial diarrhoea in several animal species as well as in humans (Turkyilmaz et al., 2013). The fecal carriage of $E$. coli in goats has been considered as a prime source of fecal contamination of food and water (Bist et al., 2014). Species of E. coli were isolated from feacal samples of goats on the basis of morphological, cultural and biochemical characteristics. The detailed results are shown in Table 2. E. coli form smooth, glistening and opalescent colonies on NA, greenish black colony with metallic sheen on EMB agar, rose pink lactose fermenter colony on MacConkey agar and slight pinkish color smooth colony on SS agar. $E$. coli showed Gram-negative (pink) rods, arranged in single, paired or in short chain, short plump rods in Gram's Method. Carbohydrate fermentation test showed that $E$. coli fermented glucose, maltose and lactose producing both acid and gas. Methyl Red (MR) test, Indole test and Motility test were positive, whereas Voges-Proskauer (VP) and Urease test were negative. These findings were similar to other studies conducted by Beutin et al. (1993), McKee et al. (1995), Abdullah et al. (2010) and Islam et al. (2017).

A total of 135 feacal samples consist of 85 diarrhoeic and 50 non diarrhoeic of goat were collected during the study period. Prevalence of $E$.coli found as $18.82 \%(\mathrm{n}=16 / 85)$ in diarrohoeic and $14 \%(\mathrm{n}=7 / 50)$ in nondiarroheic goat respectively (Table 3$)$. The overall prevalence of E. coli found as $17.04 \%(\mathrm{n}=23 / 135)$ in faecal samples of goat (Table 3). This rate was corroborate with Bhat et al. (2008) and Turkyilmaz et al. (2013) who reported 17.8\%, Ashraf (2016) who reported 14\% faecal samples positive for E. coli. Wani et al. (2003) reported $6 \%$ was positive for E. coli lower than our findings while Abdullah et al. (2010) and Adefarakan et al. (2014) reported $41.67 \%$ and $42.2 \%$ faecal samples from goats, positive for E. coli, higher than our findings. However, this variation in the prevalence might be due to sampling pattern, socio-demographic condition, climatic and geographical diversity of the goats examined. The prevalence of $E$. coli isolates found in different hospitals as $15.38 \%$ (DVHR), 21.43\% (UVHRS), 20\% (VHKTR) and 15.79\% (VHGTR) in diarrhoeic goat respectively (Table 4) while 10\% (DVHR), 17.65\% (UVHRS), 16.67\% (VHKTR) and 9.09\% (VHGTR) in non diarrhoeic goat respectively (Table 4). The overall prevalence of $E$. coli isolates found in different hospitals as $13.04 \%$ (DVHR), 20\% (UVHRS), 18.92\% (VHKTR) and 13.33\% (VHGTR) respectively. Table 5 revealed age wise distribution of $E$. coli isolates were $26.42 \%$ in day old to 1 year, $10.53 \%$ in $1-2$ years and $11.36 \%$ in above 2 years age of goat respectively. The prevalence of $E$. coli infection in kids was higher compare to young and adult. The reasons behind higher rate in kids might be due to lack of proper acquired immunity, susceptibility to various E. coli pathotypes, nutritional insufficiency, lack of bio-security and hygienic condition in the farms (Zaki et al., 2010; Jafari et al., 2012). E. coli has been reported as the important causative agent of diarrhoea that causes great economic losses in the farming industry (Gokce et al., 2010). Goats have been identified as major reservoirs which cause asymptomatic infections in animals and which can pass through the food chain to cause clinical disease in man (Arshad et al., 2006; Kiranmayi et al., 2010). E. coli infection is particularly a challenge for the rural communities who live in close proximity of goats, and have no or least knowledge about pathogenicity of bacteria and the transmission of disease. Public Health awareness including safe and hygienic practices, are of prime importance in decreasing the occurrence of E. coli infection and its spread to humans especially to the individuals closely associated with rearing and management of goats.

Table 1. Number of fecal samples collected from different areas of Rangpur District.

\begin{tabular}{lll}
\hline \multirow{2}{*}{ Name of veterinary hospital } & \multicolumn{2}{c}{ Total number of samples collected } \\
\cline { 2 - 3 } & Diarrhoeic samples & Non diarrhoeic samples \\
\hline DVHR & 13 & 10 \\
UVHRS & 28 & 17 \\
VHKTR & 25 & 12 \\
VHGTR & 19 & 11 \\
Total & 85 & 50 \\
Grand total & 135 & \\
\hline
\end{tabular}

Legends: DVHR = District Veterinary hospital, Rangpur; UVHRS = Upazila Veterinary Hospital, Rangpur Sadar; VHKTR = Veterinary Hospital Kaunia Thana, Rangpur; VHGTR = Veterinary Hospital Gangachara Thana, Rangpur. 
Table 2. Cultural, morphological and biochemical properties of $E$. coli from fecal sample.

\begin{tabular}{lll}
\hline & \multicolumn{1}{c}{ Test parameter } & Observation \\
\hline & Nutrient broth & Turbidity of the media \\
Nulture media & Nutrient agar & Smooth, glistening and opalescent colony \\
& EMB (Eosin methylene blue) agar & Greenish black colony with metallic sheen \\
& SS (Salmonella-Shigella) agar & Rose pink lactose fermenter colony \\
Morphology & GN, pink color, single or paired, small rod shaped \\
Biochemical tests & & Slight pinkish smooth colony \\
& Butt \& Slant yellow color & Glucose, Maltose, Lactose all are fermented \\
TSI & Gas bubble throughout the media & + \\
& Black colour (H2S production) & - \\
MR-VP & MR- Red color & + \\
& VP-No color change & - \\
MIU & M-Turbid whole medium & Motile \\
& I-Pink color neck of the medium & + \\
\hline
\end{tabular}

Legends: TSI $=$ Triple Sugar Iron; MR= Methyle Red; VP=Voges Prauskeur; MIU=Motility Indole Urease

Table 3. Prevalence of E. coli Isolates from diarrhoeic and non diarrhoeic goat.

\begin{tabular}{lllllll}
\hline $\begin{array}{l}\text { Samples from condition } \\
\text { of goat }\end{array}$ & No. of sample examined & $\begin{array}{l}\text { No. of } \\
\text { samples }\end{array}$ & 16 & coli positive & $\begin{array}{l}\text { Percentage of } \\
\text { positive samples }\end{array}$ & coli \\
\hline Diarrohoeic & 85 & 07 & & $18.82 \%$ & \\
Non diarrohoeic & 50 & 23 & & $14.00 \%$ & \\
Total & 135 & & & $17.04 \%$ & \\
\hline
\end{tabular}

Table 4. E. coli isolates from diarrhoeic and non diarrhoeic goat in different Veterinary hospitals in Rangpur district.

\begin{tabular}{|c|c|c|c|c|c|c|c|c|}
\hline Location & \multicolumn{2}{|c|}{ DVHR } & \multicolumn{2}{|c|}{ UVHRS } & \multicolumn{2}{|c|}{ VHKTR } & \multicolumn{2}{|c|}{ VHGTR } \\
\hline $\begin{array}{l}\text { Sample } \\
\text { source }\end{array}$ & $\begin{array}{l}\text { Diarrhoeic } \\
\text { goat }\end{array}$ & $\begin{array}{l}\text { Non } \\
\text { diarrhoeic } \\
\text { goat }\end{array}$ & $\begin{array}{l}\text { Diarrhoeic } \\
\text { goat }\end{array}$ & $\begin{array}{l}\text { Non } \\
\text { diarrhoeic } \\
\text { goat }\end{array}$ & $\begin{array}{l}\text { Diarrhoeic } \\
\text { goat }\end{array}$ & $\begin{array}{l}\text { Non } \\
\text { diarrhoeic } \\
\text { goat }\end{array}$ & $\begin{array}{l}\text { Diarrhoeic } \\
\text { goat }\end{array}$ & $\begin{array}{l}\text { Non } \\
\text { diarrhoeic } \\
\text { goat }\end{array}$ \\
\hline $\begin{array}{l}\text { No. of the } \\
\text { sample } \\
\text { examined }\end{array}$ & 13 & 10 & 28 & 17 & 25 & 12 & 19 & 11 \\
\hline $\begin{array}{l}\text { No. \& } \% \\
\text { positive of } \\
\text { E. coli } \\
\text { No. \& \% }\end{array}$ & $\begin{array}{l}02 \\
(15.38)\end{array}$ & $\begin{array}{l}01 \\
(10.00)\end{array}$ & $\begin{array}{l}06 \\
(21.43)\end{array}$ & $\begin{array}{l}03 \\
(17.65)\end{array}$ & $\begin{array}{l}05 \\
(20.00)\end{array}$ & $\begin{array}{l}02 \\
(16.67)\end{array}$ & $\begin{array}{l}03 \\
(15.79)\end{array}$ & $\begin{array}{l}01 \\
(09.09)\end{array}$ \\
\hline $\begin{array}{l}\text { Total } \\
\text { distribution } \\
\text { of } E \text {. coli }\end{array}$ & \multicolumn{2}{|c|}{$03(13.04 \%)$} & \multicolumn{2}{|c|}{$09(20.00 \%)$} & \multicolumn{2}{|c|}{$07(18.92 \%)$} & \multicolumn{2}{|c|}{$04(13.33 \%)$} \\
\hline
\end{tabular}

Legends: DVHR = District Veterinary hospital, Rangpur; UVHRS = Upazila Veterinary Hospital, Rangpur Sadar; VHKTR = Veterinary Hospital Kaunia Thana, Rangpur; VHGTR = Veterinary Hospital Gangachara Thana, Rangpur.

Table 5. Age wise distribution of E. coli isolates.

\begin{tabular}{llll}
\hline Age of goats & No. of sample examined & No. of $\boldsymbol{E}$. coli positive samples & $\begin{array}{c}\text { Percentage of } \boldsymbol{E} \text {. coli } \\
\text { positive samples }\end{array}$ \\
\hline Day old-1 year & 53 & 14 & $26.42 \%$ \\
01-2 years & 38 & 04 & $10.53 \%$ \\
>2 years & 44 & 05 & $11.36 \%$ \\
\hline
\end{tabular}




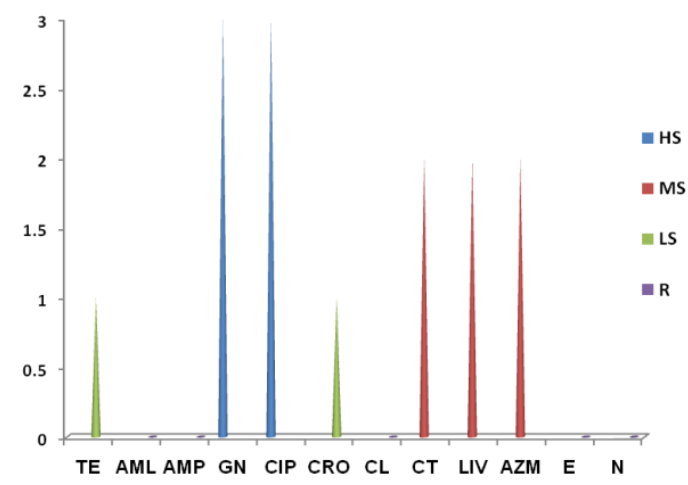

Figure 1. Antibiogram profile of E. coli against tetracycline (TE), amoxicillin (AML), ampiciline (AMP), gentamicin (GN), ciprofloxacin (CIP), ceftraexon (CRO), Cloxacillin(CL), Colistin (CT), levofloxacin (LIV), Azithromycin(AZM), Erythromycin (E) and neomycin (N)

Antibiogram means the test that is done in laboratory or in-vitro condition to detect the sensitivity of antibiotics against certain bacteria which is responsible for specific diseases. On the other hand, this test is done to measure the ability of antibiotics to prevent the growth of bacteria in in-vitro condition or in a suitable or in a suitable environment outside the host body due to the following importance this test was done. Antibiotic sensitivity test was performed by Agar disc diffusion methods. The present study revealed that the E. coli isolates of goat were highly sensitive to ciprofloxacin and gentamicin while moderately sensitive to colistin, livofloxacin and azithromycin and less sensitive to ceftraexon and tetracyclin (Figure 1). The isolates of goat E. coli were resistant to amoxycillin, ampicillin, cloxacillin, erythromycin, and neomycin (Figure 1). It has been reported that isolates of $E$. coli from humans and animals express high resistance to common antibiotics (Kang et al., 2005). Adefarakan et al. (2014) reported E. coli was frequently resistant to amoxicillin while Rashid et al. (2006) reported E. coli was frequently resistant ampicillin and highly sensitive against chloramphenicol, ciprofloxacin, norfloxacin and gentamycin. Islam et al. (2016) found $E$. coli isolates were high level of resistant against ampicillin and amoxicillin-clavulanic acid and highly sensitive to ceftriaxone, cefotaxime and gentamicin. The findings of our study was also similar to Radwan et al. (2014) who reported that $E$. coli was resistance to ampicillin and amoxiclillin. Begum et al. (2015) who reported E. coli was highly sensitive to ciprofloxacin followed by gentamicin and tetracycline. Studies on antimicrobial susceptibility of E. coli from different animal species showed an increase in the incidence of resistance over the years as a result of the widespread use of antibiotics in animals (Cid et al., 1996). However prescription of antimicrobials precedes the antimicrobial sensitivity test and antibiotic control strategy should be regulated to prevent the emergence of the drug resistance.

\section{Conclusions}

Goats are potential and economic livestock of Bangladesh. A large number of goat populations are decreasing due to diarrhoea caused by Escherichia coli in every year. The presence of $E$. coli in animal faeces provides the potential for these organisms to enter the food chain via faecal contamination, from animal to human contact, both direct and indirect, human-to-human contact. Goat meat can transmit infections and diseases either through handling during preparational procedures or as a result of ingestion by the consumer. The incidence of multiple antibiotic resistance in $E$. coli isolated from apparently healthy goats is high in the study area continues to be the challenge for the people residing in the rural areas where the peoples live in close proximity of goats have least knowledge about the pathogenecity of the bacteria. Hence, indiscriminate use of antibiotics in the animal husbandry sector should be discouraged.

\section{Conflict of interest}

None to declare.

\section{References}

Abdullah ASM, MSR Khan, M Alam, F Haq and J Hassan, 2010. Isolation and molecular characterization of Escherichia coli from goat of apparently healthy and clinical cases. Bangladesh Journal of Microbiology, 27: 14-17. 
Adefarakan TA, AO Oluduro, OM David, AO Ajayi, AB Ariyo and CD Fashina, 2014. Prevalence of antibiotic resistance and molecular characterization of Escherichia coli from faeces of apparently healthy rams and goats in Ile-Ife, southwest, Nigeria. Ife Journal of Science, 16: 447-460.

Arshad R, S Farooq and S Shahid-Ali, 2006. Manipulation of different media and methods for cost-effective characterization of Escherichia coli strains collected from different habitats. Pak. J. Bot., 38: 779-789.

Ashraf I, 2016. Studies on isolation and characterization of Escherichia coli from sheep, goats and their handlers. Master's Thesis, Division of Veterinary Public Health and Epidemiology Sher-e-Kashmir University of Agricultural Sciences \& Technology of Jammu Main Campus, Chatha, Jammu -180009 .

Begum S, GC Hazarika and S Rajkhowa, 2015. Prevalence and antimicrobial susceptibility pattern of shiga toxin producing Escherichia coli (STEC) from pigs and cattle. Int. J. Vet. Sci., 4: 221-223.

Bhat MA, Y Nishikaw and SA Wani, 2008: Prevalence and virulence gene profiles of Shiga toxin-producing Escherichia coli and enteropathogenic Escherichia coli from diarrhoeic and healthy lambs in India. Small Rumin. Res., 75: 65-70.

Bist B, B Sharma and U Jain, 2014. Virulence associated factors and antibiotic sensitivity pattern of Escherichia coli isolated from cattle and soil. Vet. World, 7: 369-372.

Biswas PK, GM Uddin, H Barua, K Roy, D Biswas, A Ahad and NC Debnath, 2006. Causes of loss of Sonali chickens on smallholder households in Bangladesh. Prev. Vet. Med., 76: 185-195.

Blood DC, AJ Henderson, JH Arundel and Gay CC, 1968. A text book of the diseases of cattle, sheep, Goat, pigs and horses. 05th edition, pp. 467.

Beutin L, D Geier, H Steinrück, S Zimmermann and F Scheutz, 1993. Prevalence and some properties of verotoxin (Shiga-like toxin)-producing Escherichia coli in seven different species of healthy domestic animals. J. Clin. Microbiol., 31: 2483-2488.

Carter GR and JR Cole, 1991. Diagnostic Procedure in Veterinary Bacteriology and Mycology. $5^{\text {th }}$ Ed. Academic Press Inc. pp 372-373.

Chulasiri M and O Suthienkul, 1989. Antimicrobial resistance of Escherichia coli isolated from Animals. Vet. Microbiol., 21: 189-194.

Cid O, S Piriz, JA Riuz-Santa-Quiteria, S Vadillo and R de-la-Fuente, 1996. In vitro susceptibility of Escherichia coli strains isolated from diarrhoeic lambs and goat kids to 14 antimicrobial agents. Journal of Veterinary Pharmacology Therapy, 19: 397-401.

Cowan ST, 1985). Cowan and Steels Manual for Identification of Medical Bacteria. $2^{\text {nd }}$ Edition, Cambridge University Press, London.

CLSI, 2012. Performance standards for antimicrobial disk susceptibility tests; approved standard- 11th Edn., CLSI document M02-A11. Wayne, PA: Clinical and Laboratory Standards Institute.

Debnath NC, BK Sil, SA Selim, MAM Prodhan and MR Howlader, 1990. A respective study of calf morbidity and mortality in small holder traditional farms in Bangladesh. Prev. Vet. Med., 09: 1-7.

Dho M and JP Lafont, 1984. Adhesive properties and iron uptake ability of E. coli lethal and nonlethal for chicks. Avian Dis., 28: 1016-1025.

Drasar BS and MJ Hill, 1974. Human intestinal flora. Academic Press Ltd. London, United Kingdom. p. 36-43.

Fairbrother JM and E Nadeau, 2006. Escherichia coli: On-farm contamination of animals. Review of Science and Technology, 25: 555-569.

Gokce E, A Unver and HM Erdogan. 2010. Enteric pathogens in the aetiology of diarrhoea in neonatal lambs. Kafkas Univ. Vet. Fak. Derg., 16: 717-722.

Holt JG, NR Krieg, HA Sneath, JT Staley and ST William, 1994. Bergey's Mannual of Determinative Bacteriology. $9^{\text {th }}$ edn. Baltimore: Williams and Wilkins.

Islam K, A Ahad, M Barua, A Islam, S Chakma, C Dorji, MA Uddin, S Islam and ASML Ahasan, 2016. Isolation and epidemiology of multidrug resistant Escherichia coli from goats in Cox's Bazar, Bangladesh. Journal of Advanced Veterinary and Animal Research, 3: 166-172.

Jafari A, M Aslani and S Bouzari, 2012. Escherichia coli: a brief review of diarrheagenic pathotypes and their role in diarrheal diseases in Iran. Iranian J. Microbiol., 4: 102-117.

Kang HY, YS Jeong, JY Oh, SH Tae, CH Choi, DC Moon, WK Lee, YC Lee, SY Seol and DT Cho, 2005. Characterization of antimicrobial resistance and class 1 integrons found in Escherichia coli isolates from humans and animal in Korea. J. Antimicrob. Chemother., 55: 639-644.

Khan MFR, MB Rahman, MSR Khan, KHMNH Nazir and M Rahman, 2005. Antibiogram and plasmid profile analysis of isolated poultry Salmonella of Bangladesh. Pak. J. Biol. Sci., 8: 1614-1619.

Kiranmayi CB, N Krishnaiah and EN Mallika, 2010. Escherichia coli O157:H7 - An emerging pathogen in foods of animal origin. Vet. World, 3: 382-389. 
Larulle L, 1889. Cellule, 05:59.

Levine MM, 1987. Escherichia coli that cause diarrhoea: enterotoxigenic, enteropathogenic, enteroinvasive, enterohaemorrhagic and enteroadherent. Journal of Infected Disease, 155: 377-89.

Merchant IA and RA Packer 1976. Veterinary Bacteriology and Virology $7^{\text {th }}$ edn, the Iowa State University Press. Ames, Iowa, USA. pp. 286-306.

McKee ML, AR Melton-Celsa, RA Moxley, DH Francis and AD O'Brien, 1995. Enterohemorrhagic Escherichia coli $\mathrm{O} 157: \mathrm{H} 7$ requires intimin to colonize the gnotobiotic pig intestine and to adhere to HEp-2 cells. Infect. Immun., 63: 3739-3744.

OIE, 2000. Office International Epizootics. Manual of standards for diagnostics test and vaccines. OIE Guide-2.

Radostits OM, DC Blood and CC Gay, 1995. A Textbook of Disease of Cattle, Sheep, Pigs, Goats and Horses. Veterinary Medicine. 08th Edn., Philadelphia, Sydney, Tokyo, Toronto, pp: 697.

Radwan IA, HSH Salam, SAA Alwanis and MA Yahia Al-Sayed, 2014. Frequency of some virulence associated genes among multidrug-resistant Escherichia coli isolated from septicemic broiler chicken. International Journal of Advanced Research, 2: 867-874.

Rashid M, SK Kotwal and MA Malik, 2006. Multiple drug resistance and serotyping of E. coli isolates from bovine mastitis milk in and around Jammu. Journal of Veterinary Public Health, 4: 47-49.

Smith HW, 1965. The development of the flora of the alimentary tract in young animals. J. Pathol. Bacteriol., 90: 495-513.

Turkyilmaz1 S, S Eskiizmirliler, S Tunaligil and B Bozdogan, 2013. Identification, characterization and molecular epidemiology of Escherichia coli isolated from lamb and goat kids with diarrhea. ACTA VET. BRNO, 82: 357-362.

Turner SM, A Scott-Tucker, LM Cooper and IR Henderson, 2006. Weapons of mass destruction: virulence factors of the global killer enterotoxigenic Escherichia coli. FEMS Microbiol. Lett., 263: 10-20.

Wani SA, MA Bhat, I Samanta, Y Nishikawa and AS Buchh, 2003: Isolation and charecterization of shiga toxinproducing Escherichia coli (STEC) and enteropathogenic Escherichia coli (EPEC) from calves and lambs with diarrhea in India. Lett. Appl. Microbiol., 37: 121-126.

Zaki MS, NS Ata and I Shalaby, 2010. Diarrhoea in Neonatal baraki kids-goats. Life Science Journal, 7: 93-97.

Zinnah AM, 2007. Characterization and drug sensitivity pattern of Escherichia coli isolated from different biological and environmental sources. M.S. Thesis, Department of Microbiology and Hygiene, Bangladesh Agricultural University, Mymensingh. p. 20. 